\title{
A ética dos antigos e o questionamento de nossa atualidade: o problema da moral em Michel Foucault
}

\author{
The ancient ethics and the questioning of our present: the \\ problem of the moral in Michel Foucault
}

Daniel Costa Farias*

Recebido em: 03/2015

Aprovado em: 11/2015

\begin{abstract}
Resumo: O objetivo desse trabalho é demonstrar os elementos que a pesquisa de Foucault traz para fundamentar ou contribuir para o desenvolvimento de um debate sobre a moral. Para essa pesquisa teórica usaremos principalmente os dois últimos volumes da História da Sexualidade de Foucault: "O Uso dos Prazeres" e "O Cuidado de Si", bem como outros textos da mesma temática. Com esses textos, encontramos um material consistente que propiciou o desenvolvimento de nossa pesquisa, pois é exatamente neles que o autor francês desenvolve questões $e$ argumentos diversos sobre a moral.Assim, para o autor, em sua análise genealógica da ética, nossa constituição enquanto indivíduo passará sempre pelas regras de condutas das quais estamos expostos e fazemos parte. Portanto, o estudo de Foucault pode colaborar bastante para o pensamento acerca da moral, uma vez que o autor busca entender como os indivíduos se constituem na relação com os princípios normativos e os códigos morais.
\end{abstract}

Palavras-chave: Michel Foucault, Moral, Autocontrole, Ética

Abstract: The aim of this study is to demonstrate the elements
that Foucault brings research to support or contribute to the
development of a debate on morals. For this theoretical
research will mainly use the last two volumes of the History of
Sexuality Foucault: "The Use of Pleasures " and "The Self
Care " as well as other texts of the same theme. With these

* Graduação em Psicologia pela Universidade Estadual da Paraíba (UEPB)

e Mestre em Sociologia pela Universidade Federal da Paraíba (UFPB).

Email: daniel.farias.c@hotmail.com

Problemata: R. Intern. Fil. v.6, n. 3(2015), p 146-170 ISSN 2236-8612 doi:HTTP://dx.doi.org/10.7443/problemata.v6i3.23557 
texts we find a consistent material that led to the development of our research, it is precisely in them that the french author develops various issues and arguments about morality. Thus, for the author, in his genealogical analysis of ethics, our constitution as an individual will always pass by the rules of conduct of which we are exposed and we are part. Therefore, Foucault's study can collaborate enough for thought about the moral, as the author seeks to understand how individuals are in relation to the normative principles and the moral codes.

Keywords: Michel Foucault, Moral, Self Control, Ethics

\section{Introdução}

Devido a considerável influência de Nietzscheem toda obra de Michel Foucault, podemos pensar a obra do filósofo francês como uma genealogia de nossa moral moderna. A questão da moral em Foucault pode ser observada de forma indireta em seus livros da fase arqueológica, bem como também vemos essa mesma situação na fase genealógica. Contudo, observamos essa situação mudar consideravelmente na década de 1980, década essa onde o autor vai transformar de maneira radical todo seu projeto de estudo da modernidade para regressar até a antiguidade greco-romana e avaliar como as práticas e princípios - os exercícios do cuidado de si - se constituíram como domínio de prática moral e um modo de subjetivação caracterizado como uma "estética da existência" (FOUCAULT, 2006b). O filósofo ressalta que uma das principais diferenças de uma moral antiga para uma moral moderna seria pelo fato, bastante restrito, de que a moral antiga era específica para as elites e a moral moderna se fundou na base cristã de ser e pretender alcançar a todos (FOUCAULT, 1994, p. 24-25).

Assim, quando falamos que o tema da moral é indireto nos primeiros livros de Foucault, queremos dizer que sua preocupação, como objeto de pesquisa, não era a "moral" propriamente dita, pois esse mesmo problema já estaria inserido em suas pesquisas de forma espalhada e dissolvida no tema da construção da modernidade. Desse modo, na pesquisa dita arqueológica, o objetivo de Foucault foi fazer uma arqueologia do saber moderno, onde a intenção de sua investigação é entender como os saberes das ciências humanas se formaram na modernidade (MACHADO, 2000, p.142). Com o aparecimento da psiquiatria, da psicologia, das ciências sociais e outras 
ciências "do homem", por exemplo, o autor mostra que esses saberes nasceram de uma situação muito específica, de suas condições históricas, e que se adequavam a uma moral vigente.

Com a genealogia do poder, Foucault suplementa essas análises do aparecimento e a possibilidade de uma ciência do homem com as relações de poder intrínsecas nessas mesmas relações (MACHADO, 2000, p.187). A pergunta agora é saber o como e o porquê dessas relações de poder. $\mathrm{O}$ corpo, como objeto das relações de poder, é acompanhado, em nossa modernidade, por saberes que avaliam o quanto e o quê esse corpo pode produzir. Surge então uma política preocupada com a vida (bios).Abiopolítica das populações, que legitima o controle e a gestão para uma maior produtividade da vida em seu máximo, é interesse de Foucault. Portanto, esse efeito dobio-poder é a produção de almas, saberes, corpos, de moral (EWALD, 1993, p. 28).

Apesar disso, apenas nos livros $O$ uso dos prazeres e $O$ cuidado de si é que vemos Foucault problematizar a moral (greco-romana) -ainda que esse trabalho esteja incompleto, pois o autor morreu antes de terminar seu projeto da História da Sexualidade. Para Foucault é importante saber quais circunstâncias levaram a atividade sexual a ser objeto de uma preocupação moral e de um cuidado ético (FOUCAULT, 1994, p. 14). A conduta sexual dos antigos traz esclarecimentos para o autor no sentindo que essas inquietações e esses cuidados estão ligados entre si levando o indivíduo a se reconhecer como sujeito moral de sua própria conduta. Foucault, em seus últimos estudos, não está apenas preocupado em saber como o indivíduo está obrigado a agir diante de certos princípios éticos ou da obrigação de se comportar adequadamente a partir das regras morais. Sua investigação vai ser na constituição do indivíduo e o que importa para o autor é saber como esses indivíduos, na relação com os códigos morais e princípios éticos, agem e estabelecem relações com eles mesmos.

Nas ciências humanas, Foucault é cada vez mais lido e utilizado em várias pesquisas e estudos (SMITH, 1999, p. 81; BINKLEY et al, 2010, p. 54). Contudo, sua última fase não é tão trabalhada pelas pesquisas desta disciplina, talvez por se referir a um momento histórico muito distante da modernidade (época em que tais ciências nasceram e assim foram possíveis). Em nosso trabalho, argumentamos de maneira distinta dessa 
tendência por considerar que o estudo de Foucault pode colaborar bastante para o pensamento acerca da moral, uma vez que o autor busca entender como os indivíduos se constituem na relação com os códigos morais e os princípios normativos. Sendo assim, o presente argumento busca apresentar os elementos que a pesquisa de Foucault traz para fundamentar ou contribuir para o desenvolvimento de um debate sobre a moral.

\section{Moral e o uso dos prazeres}

A genealogia de Foucault nos demonstra aspectos importantes sobre a ética e a moral da antiguidade grecoromana. Esse estudo de Foucault sobre o "presente" retoma uma pergunta de Kant da época do iluminismo: quem somos nós, nesse momento da história? "[...] talvez, o mais evidente dos problemas filosóficos seja a questão do tempo presente e daquilo que somos atualmente [...]" (FOUCAULT, 1995, p. 239). Nesse ponto, o próprio Foucault confessa sua influência de Nietzsche e que, portanto, também estaria fazendo uma espécie de genealogia da moral. (FOUCAULT, 2006b). A moral que o autor recupera em seus últimos trabalhos esta relacionada com os sentidos de ética; como uma relação que os indivíduos têmcom eles mesmos e as diversas práticas de liberdade.

Quando Foucault estuda os gregos e os romanos, pode-se perceber que o sentido de moral que o autor demonstra não é o mesmo a qual estamos acostumados; de uma moral que todos nós devemos seguir - uma moral de valor universal. $\mathrm{Na}$ introdução do segundo volume da História da Sexualidade, $O$ uso dos prazeres, Foucault (1994) faz um pequeno resumo de sua obra e propõe explicar o que pretende fazer de diferente em suas novas pesquisas. Para o autor, o que passa a ser fundamental em seus últimos estudos é entender e analisar as práticas pelas quais os indivíduos foram levados a prestar atenção neles mesmos e a cuidar de si (FOUCAULT, 1994, p.11). Assim, uma pergunta se torna importante para o autor: porque o comportamento sexual e as atividades ligadas aos prazeres, ao corpo, são alvo de uma preocupação moral? Porque, a partir de uma atenção moral em certas sociedades, se deu tanta importância para esse assunto, mais até do que para questões alimentares ou cívicas? Uma resposta aparece de imediato: é que 
esse comportamento, o sexual, é alvo de inúmeras interdições e sua infração se torna algo grave (FOUCAULT, 1994, p.14). A preocupação moral pode muito bem aparecer sem nenhuma interdição acentuada, sem exatamente estar ligada a nenhuma obrigação ou uma lei geral. Foucault comenta que interdições e proibições não significam exatamente a mesma coisa de uma problematização moral. Porque então os comportamentos sexuais são alvo de uma problematização moral?

Se voltarmos para a antiguidade, sobretudo aos gregos, perceberemos uma preocupação e um cuidado com a austeridade sexual. Esses temas de austeridade, por exemplo, não necessariamente combinam com proibições e interdições religiosas. Esse pensamento de sempre ligar moral a uma proibição e coerção é bastante comum, mas não é bem assim que vemos, depois de ler e estudar os textos sobre a antiguidade greco-romana (FOUCAULT, 1994, p.24). As mulheres, por exemplo, em relação a essas questões morais relacionadas aos prazeres do corpo, não eram muito citadas nos escritos da época. Suas obrigações eram coisas bem estritas e demarcadas, algo muito pouco comentado. Essa austeridade sexual era algo exclusivo dos homens. Uma moral de homens, pensada e criada para os homens "livres" do tempo, ou seja, algo muito específico e voltado para o ponto de vista das elites constituída apenas por homens. Portanto, serão práticas que, como veremos, adquirem diversas formas durante o tempo.

Por que na antiguidade foi a respeito do corpo, e da verdade, que a prática dos prazeres foi questionada? Por que isso foi aos poucos ganhando uma considerável austeridade? Para entender essas perguntas, de acordo com Foucault, é necessário observar as transformações de uma "moral". Assim, o autor vai primeiramente definir moral como "um conjunto de valores e regras de ação propostas aos indivíduos e aos grupos por intermédio de aparelhos prescritivos diversos" (FOUCAULT, 1994, p.26). Esses aparelhos podem ser a família, a igreja, a escola, etc. Tanto podem ser demonstrados em doutrinas, bem como podem ser bastante difusos e pouco específicos, levando assim para vários entendimentos. Um código moral seria esse conjunto dos aparelhos prescritivos. Depois, Foucault vai também entender "moral" como o comportamento dos indivíduos em relação às regras e valores que lhe são recomendados. Para o autor é importante entender a maneira 
pelas quais os grupos e indivíduos se conduzem em relação a esses conjuntos prescritivos que são explícitos e implícitos, dependendo da cultura, em uma "moralidade dos comportamentos". Foucaultobserva que a partir de um determinado momento é necessário, para o indivíduo, conduzirse, constituir a si mesmo como sujeito moral, baseado nesses mesmos elementos prescritivos.

Existem várias maneiras de se conduzir moralmente e não apenas como agente, mas também como sujeito moral de uma ação. Tanto se pode apenas seguir uma regra, uma interdição, bem como controlar os desejos e as tentações que aparecem. Isso é de todo o interesse de uma prática moral. "O indivíduo estabelece uma relação com a regra e se vê na obrigação, ou dever, de coloca-la em prática" (FOUCAULT, 1994, p.27).

Para Foucault (1994) uma ação moral não é uma atitude somente em si mesma, ela é também, por sua entrada, o lugar que ocupa no conjunto das condutas dos indivíduos. Então, como ressalta o autor, para uma ação ser moral não se deve apenas reduzir a conformidade com as regras e as leis, essa ação moral também traz uma relação do indivíduo consigo, uma constituição de si enquanto sujeito moral. Estabelecer para si um modo de ser que será a realização moral dele mesmo. Conhecerse, controlar-se, vigiar-se, transformar-se. Sem essas "práticas", todas as ações morais ficam enviáveis.

Para ser dita "moral" uma ação não deve se reduzir a um ato ou a uma série de atos conformes a uma regra, lei ou valor. É verdade que toda ação moral comporta uma relação ao real em que se efetua, e uma relação ao código que se refere; mas ela implica também uma certa relação a si; essa relação não é simplesmente "consciência de si", mas constituição de si enquanto "sujeito moral", na qual o indivíduo circunscreve a parte dele mesmo que constitui o objeto dessa prática moral, define sua posição em relação ao preceito que respeita, estabelece para si um certo modo de ser que valerá como realização moral dele mesmo; e, para tal, age sobre si mesmo, procura conhecer-se, controla-se, põese à prova, aperfeiçoa-se, transforma-se. Não existe ação moral particular que não se refira à unidade de uma conduta moral; nem conduta moral que não implique a constituição de si mesmo como sujeito moral; nem tampouco constituição do sujeito moral sem "modos de subjetivação" sem uma "ascética" ou sem "práticas de si” que as apoiem. A ação moral é indissociável dessas 
formas de atividades sobre si, formas essas que não são menos diferentes de uma moral a outra do que os sistemas de valores, de regras e de interdições (FOUCAULT, 1994, p.28-29).

O interesse de Foucault, portanto, não vai ser em fazer uma história da moral, nem da moralidade, nem das mentalidades, mas sim em fazer uma história pela qual os indivíduos foram convocados, a partir de um momento particular, a serem constituídos como sujeitos de conduta moral. Analisar as relações estabelecidas consigo mesmo, o conhecimento de si, a transformação de si, analisar a história e estudar as formas de subjetivação moral e das práticas que garantam essas formas; uma história e um estudo das experiências é o interesse do filósofo. Segundo o autor, se for verdade que toda moral baseia-se em dois aspectos, o dos códigos de conduta e modos de subjetivação, e que eles estão associados um ao outro, é importante admitir que em muitas morais são exatamente os códigos de condutas que prevalecem (FOUCAULT, 1994). Houve na antiguidade uma moral voltada para a ética, outra moral voltada para os códigos de conduta, como também conformidades e conflitos entre essas morais que estavam muitas vezes em combinação.

O que se observa, para Foucault, é que na Antiguidade foram as práticas de si que sobressaíram em relação aos códigos do que é permitido ou não. Mesmo nas necessidades de respeitar regras, o que importava era que o indivíduo não fosse levado pelos desejos e prazeres, pois assim perderia o domínio de si, o essencial seria manter seus sentidos em estado de tranquilidade e serenidade, livre da escravidão das paixões e sendo plenamente soberano sobre si mesmo. Foi uma moral vista do pensamento greco-romano até a constituição da doutrina e moral cristã - e que passou por diversas mudanças e transformações no que diz respeito ao cuidado de si - a que o autor vai dedicar seus últimos anos de estudo.

Foucault observa que na Antiguidade não se conhecia uma "sexualidade" como nós hoje a denominamos. Os gregos, por exemplo, usavam de diversos nomes para aquilo que na modernidade usamos como "sexual". O vocabulário é extenso e foram encontrados pelo autor termos para práticas precisas e que hoje recebem outros nomes. Nossas noções desses termos englobam um campo muito mais amplo e apresentam outra 
realidade associada à moral e aos saberes dominantes. Em comparação com a idade média, ou com a modernidade, é notável que os antigos não se preocupavam da mesma forma com as questões morais. Porém, uma coisa é fundamental: eles se preocupavam, mesmo que de maneira distinta e breve, com essas questões e havia nisso um reconhecimento de um problema moral (FOUCAULT, 1994, p. 35-36). Fou cault retoma a moral sexual da época de alguns escritos de filósofos gregos, tais como Xenofonte, Platão e Aristóteles e observa quatro noções importantes. A primeira é a noção de aphrodisia, que no comportamento sexual era apreendido como "substância ética"; a segunda é do "uso" de chresis, que via o tipo de sujeição que essas práticas deveriam submeter para serem moralmente valorizadas; a noção de enkrateia, que significa o domínio e a atitude que se deve ter de si mesmo para se constituir como um sujeito moral; e por último a noção desophrosune, que em sabedoria caracteriza o sujeito moral em sua realização.

A noção de aphrodisia pode ser entendida como algo ligado aos atos, ou gestos, que proporcionam uma certa forma de prazer. Pois a partir disso os gregos se perguntavam com que força se é levado pelos prazeres e pelos desejos. Como dominar essa força? Como conviver com ela? (FOUCAULT, 1994, p.3940). Já a noção de chresis pode ser entendida pela maneira como o individuo conduz sua vida sexual. De que maneira, perguntam os gregos, obter o prazer "como convém"? Essa noção pode ser entendida como algo que passa pela necessidade, de uso para o corpo e nada mais; que passa pelo momento oportuno, uma moral do "quando convém". É também relacionada ao status, pois alguém que consegue controlar-se merece respeito (FOUCAULT, 1994, p.51-52). A noção de enkrateia pode ser entendida como uma dinâmica de uma dominação de si, uma ordem sobre certos prazeres e desejos. É preciso dominar a si mesmo, saber controlar desejos e prazeres, isso sim é uma virtude (FOUCAULT, 1994, p.62-63). E por último, a noção do que é ser "livre". Pois é importante o indivíduo comandar a si mesmo. Sendo assim, só depois que comandar a si é que pode, por exemplo, governar uma cidade, sua casa ou um grupo (FOUCAULT, 1994, p.74-75). Todas essas quatro noções são parte daquilo que se constituiu como uma moral, e que teve sua relação com a "liberdade" e a "verdade". Foucault observa a partir dos textos gregos - Platão, Diógenes, Xenofonte, Plutarco 
- que existiu todo um cuidado e a valorização de uma moral que era constituída na época e que, por sua vez, foi bastante específica assim como não era para todos os cidadãos da Grécia antiga.

Segundo Foucault, é evidente que os gregos tinham outras preocupações e outros temas relativos à moral, mas o tema sexual, ou relacionado aos desejos e prazeres, é importante, pois retoma ao cuidado e a conduta em relação a si mesmo e a um domínio de prática moral. Foucault, com isso, esclarece que muito se pensou a respeito de um passado anterior ao cristianismo que fosse do lado de uma "liberdade", porém, quando se olha mais atentamente, existiam proibições e já havia uma moral implícita. Essa moral, se assim preferirmos, não era uma lei universal, mas sim um princípio que funcionava para aqueles que quisessem - e que tinham condições para isso transformar e guiar sua vida. A austeridade sexual citada na filosofia grega nos mostra uma experiência moral que permite ao indivíduo uma transformação e condução de si mesmo.

A reflexão sobre o comportamento sexual como campo moral não constituiu entre eles uma maneira de interiorizar, de justificar ou de fundamentar em princípios certas interdições gerais impostas a todos; foi sobretudo uma maneira de elaborar, para a menor parte da população, constituída pelos adultos livres do sexo masculino, uma estética da existência, a arte refletida de uma liberdade percebida como jogo de poder. A ética sexual que está em parte na origem da nossa repousava de fato num sistema muito duro de desigualdades e de coerções (em particular a respeito das mulheres e dos escravos); mas ela foi problematizada no pensamento como a relação para um homem livre, entre o exercício de sua liberdade, as formas de seu poder, e seu acesso à verdade (FOUCAULT, 1994, p.220).

Nos primeiros séculos depois de cristo, Foucault comenta sobre algumas mudanças e lentas evoluções. Começam a haver determinadas discussões a respeito dessas práticas e as transformações parecem ser inevitáveis. 
Moral, cuidado e cultura de si

Para Foucault (2002), os dois primeiros séculos depois de Cristo são de austeridade e severidade em relação aos prazeres do corpo. A desconfiança em relação aos prazeres, a insistência no casamento e suas obrigações, um distanciamento da relação de amor que até pouco tempo se via entre homens, marca o pensamento médico e filosófico da época (FOUCAULT, 2002, p.45). Uma nova moralidade vai se constituindo e o que vem a ser importante nos textos desse momento é uma ampliação da atenção que se deve ter para consigo mesmo, vigilância, cuidado com os descompassos do corpo e da alma, respeitando a si e limitando ao máximo o uso dos prazeres. Uma reflexão moral do indivíduo em sua relação com ele próprio e, sendo assim, ele mesmo responsável por todos os seus atos.

A austeridade sexual, primeiramente, não foi um ato individualista, mas sim uma "cultura de si". Termo esse em que se entende por um princípio de ter cuidados consigo mesmo. Nessa cultura, se assim podemos nos referir, os homens devem cuidar deles mesmos, não se ocupar com a natureza, mas ocupar-se consigo mesmo (FOUCAULT, 2002, p.50). Assim, Foucault comenta que essa atividade, de cuidar de si mesmo, não é um exercício de afastamento e solidão. Ela é uma prática social que envolve vários indivíduos e situações. Portanto,como bem vemos nos textos gregos e romanos, o indivíduo preocupando consigo também se preocupa com o outro.

Essa prática e esse cuidado de si também são associadosà medicina antiga. São preocupações da época: as doenças do corpo e da alma, as paixões, a perda de equilíbrio, a passividade nas ações, e a perda e desequilíbrio que a falta de cuidado poderia causar ao indivíduo. Uma medicina específica, assim como um cuidado com o corpo e a alma, são atividades morais, pois formar-se e cuidar-se, como práticas sociais, são atividades consideradas solidárias. A severidade e austeridade para com as atitudes dos indivíduos não devem ser entendidas apenas como proibições, mas antes, como assinala Foucault, como uma maneira pela qual o indivíduo deve se construir de acordo com uma moral. O comportamento sexual, por exemplo, é uma força e foi considerado na antiguidade como algo que exige atenção. Então, nos primeiros séculos de nossa era, esses princípios ganham cada vez mais uma universalidade e passam a ser uma 
regra. Abstinência e o domínio questionam os indivíduos a todo o momento, assim como colocam a questão da verdade como foco principal na constituição do sujeito moral (FOUCAULT, 2002, p.59-60; p. 71-73).

Para Foucault, um dos aspectos desse desenvolvimento da cultura e do cuidado de si pode ser observado, por exemplo, nas práticas matrimoniais. $\mathrm{O}$ casamento, e a forma de como se lida com ele, vai servir de modelo para demonstrar essa relação com a moral. Delimitar uma prática comum do matrimonio na antiguidade é algo difícil. $O$ que vemos são vários exemplos (FOUCAULT, 2002, p. 79).Porém, se usarmos as leituras que Foucault fez dos textos sobre essa época, iremos notar como essa instituição funcionou e como isso implicava em um valor moral. Primeiramente, o casamento era um ato privado, que assim, dizia respeito à família e seu funcionamento, e não exigia nenhuma intervenção dos poderes públicos tanto da Grécia como de Roma. Era apenas a transferência da tutela do pai para o futuro marido; ou com comenta Veyne (2008), uma troca de favores, negócios entre famílias.

Para Foucault (2002), o casamento no mundo helenístico vai progressivamente tomando lugar na esfera pública e aos poucos vai ultrapassando o circulo da família para ganhar um lugar mais amplo, um significado mais amplo. Da autoridade familiar vemos o casamento passar para outra esfera: a de ser transferido para o poder público. O Adultério, de um homem casado ou uma mulher casada, é condenado em lei pela sociedade. Essa "mudança" na instituição do casamento parece, segundo o autor, ter se espalhado para as outras camadas da população. Os imperativos tanto políticos como econômicos, são importantes, porém, a formação de vínculo entre duas pessoas, como apoio moral, também ganha sua notoriedade. Não sendo apenas uma relação de contrato, de autoridade estatuária, mas também uma relação que possuía sua singularidade, suas obrigações, dificuldades e benefícios dos mais diversos. $\mathrm{O}$ casamento, como uma instituição ligada à moral, foi interrogado pelos antigos, segundo Foucault, como um modo de vida, que não passa só pelo funcionamento da cidade, mas passa pela relação de duas pessoas. Aqui, o homem deve regular sua conduta de acordo com a relação da casa. Constituir-se enquanto sujeito moral em sua relação conjugal. 
A sinceridade que eles ostentam não vale como testemunho. Trata-se de textos que proclamam, de modo voluntariamente aplicado, um ideal de conjugalidade. Não se deve toma-los por reflexo de uma situação, mas sim como a formulação de uma exigência, e é nessa qualidade justamente que eles fazem parte do real. Eles mostram que o casamento é interrogado como um modo de vida cujo o valor não é exclusivamente, nem mesmo, talvez, essencialmente, ligado ao funcionamento do oikos, mas sim a um modo de relação entre dois parceiros; eles também mostram que, nessa ligação, o homem deve regular sua conduta não somente a partir de um status, de privilégios e de funções domésticas, mas também a partir de um "papel relacional" com respeito à sua função governamental de formação, de educação, de direção, mas que se inscreve num jogo complexo de reciprocidade afetiva e de dependência reciproca. Ora, se é verdade que a reflexão moral sobre a boa conduta do casamento tinha, por muito tempo, procurado seus princípios numa análise de "casa" e de suas necessidades intrínsecas, compreende-se o surgimento de um novo tipo de problemas, em que se trata de definir a maneira pela qual o homem poderá constituir-se enquanto sujeito moral na relação de conjugalidade (FOUCAULT, 2002, p.87).

Uma coisa fica clara para Foucault ao notar o exemplo do casamento na antiguidade: cada um, nesse período, é responsável por sua própria moralidade. Para o autor, oque se observava em muitos textos da época era a elaboração de uma ética que possibilitasse constituir um indivíduo enquanto sujeito moral em relação a todas as atividades; sejam elas cívicas, pessoais ou políticas. Assim, os princípios para os prazeres estão centrados no corpo e é como esse corpo se comporta que se deve guiar as condutas, pois é o corpo que mostra a lei (FOUCAULT, 2002, p.136). Se os humanos, como observa Foucault no pensamento greco-romano, necessitam de um regime que considere os seus elementos fisiológicos, em sua completude, é porque eles tendem a dele se afastar quase que sempre por meio de suas emoções, imaginações, paixões e etc. Foi aconselhável ao sujeito da época tentar "eliminar" imaginações e emoções que o levassem ao descontrole.

Uma reflexão moral bastante acentuada sobre as atividades sexuais e relacionada às condutas é, para Foucault, o que caracteriza o começo da era cristã. Abstenção e austeridade são recomendadas, e a virgindade é mais indicada do que o uso

Problemata: R. Intern. Fil. v.6, n. 3(2015), p 146-170 ISSN 2236-8612 
dos prazeres. O casamento é valorizado, bem como o adultério é condenado. Entretanto, se analisarmos esse ponto a partir dos elementos que Foucault nos fornece, o ato sexual, desde muito antes do cristianismo, e até mesmo na Grécia antiga, já era considerado como "perigoso", trabalhoso e de difícil dominação. Sua prática há muito tempo é inserida dentro de um contexto moral, onde é inserida em regras e passa por um regime bastante prudente. Todo um cuidado com o corpo e a saúde foram motivos para uma elaboração de uma moral cautelosa. Então, a questão principal não era uma preocupação exclusiva com o sexo ou com outro tema específico, mas era uma preocupação em não perder o domínio de si. Manter e estabelecer um conjunto de preceitos e práticas para o controle de si mesmo, uma plena soberania sobre si mesmo, era uma preocupação dos antigos e razão da construção de uma moral.

Essa moral sofrerá mudanças no decorrer do tempo, a partir do cristianismo, sobre o aspecto de abdicação das vontades e, mais tarde, em nossa modernidade, a moral ganha formas de ter acesso e constante ambição de saber a "verdade". Transforma-se em uma constante "vontade de saber", tema que Foucault (2006a) trabalhou no primeiro volume da História da Sexualidade. Contudo, o filósofo ainda nos traz mais temas para discussão quando se trata da moral nos antigos.

A respeito da moral, os antigos deixaram exemplos importantes. Foucault (2006b) comenta que a moral antiga se endereçava a um pequeno numero de pessoas, a elite da época constituída exclusivamente pelos cidadãos livres do sexo masculino. Porém, a moral cristã, posterior a moral grecoromana, é bastante diferente da situação anterior, pois é uma moral que tinha uma pretensão maior.

Com o cristianismo, veio a se instaurar lentamente, progressivamente uma mudança em relação às morais antigas, que eram, essencialmente, uma prática, um estilo de liberdade. Naturalmente, havia também certas normas de comportamento que regulavam a conduta de cada um. Porém, a vontade de ser um sujeito moral e a procura de uma ética da existência era principalmente, na Antiguidade, um esforço para afirmar a própria liberdade e dar a sua própria vida uma certa forma na qual podia se reconhecer e ser reconhecido por outros e onde a posteridade mesma poderia encontrar como exemplo. Esta elaboração da própria vida como uma obra de arte pessoal, ainda que obedecendo certos

Problemata: R. Intern. Fil. v.6, n. 3(2015), p 146-170 ISSN 2236-8612 
cânones coletivos, estava ao centro, me parece, da experiência moral, da vontade moral na Antiguidade, enquanto que, no cristianismo, com a religião do texto, a ideia de uma vontade de Deus, o princípio de uma obediência, a moral assume muito mais a forma de um código de regras (somente certas práticas ascéticas estavam mais ligadas ao exercício de uma liberdade pessoal). Da Antiguidade ao cristianismo, passou-se de uma moral que era essencialmente uma busca de uma ética pessoal a uma moral como obediência a um sistema de regras. E se eu sei me interessar pela Antiguidade, é que, por toda uma série de razões a ideia de uma moral como obediência a um código de regras está em processo, presentemente, de desaparecimento; já desapareceu. E à essa ausência de moral, responde, deve responder, uma busca de uma estética da existência (FOUCAULT, 2006b, p. 289-290).

Foucault (2006b) comenta que para os antigos era importante, antes de tudo, aprender a governar a si mesmo como condição de regime de vida. Uma moral como princípio de uma ética pessoal e modelo de uma "estética da existência". A tarefa dessa estética da existência cabia somente às minorias privilegiadas, liberadas de toda função na reprodução material e que podiam empregar todas suas forças para realizar o refinamento de seus estilos de vida. Trocando em miúdos: era uma moral para as elites. Essas elites eram constituídas pelos cidadãos livres da época. Portanto, ficaram de fora dessas práticas de estética e estilização: as mulheres, as crianças, os plebeus e os escravos (um número considerável de indivíduos). Com essa estética da existência, como um estilo de vida, Foucault comenta as práticas baseadas numa ética dos prazeres e não do sexo. Dando ênfase aos prazeres e não ao sexo, os sujeitos poderiam reinventar-se, sem recorrer às identidades criadas pelo sistema de nominação tal como vemos a partir da moral cristã.

\section{Avaliação das perspectivas}

Ao considerar a pesquisa de Foucault sobre a antiguidade greco-romana, algumas perguntas aparecem como necessárias. Primeiramente,como essas práticas, descritas em $O$ uso dos prazeres e $O$ cuidado de si, podem ajudar nos debates acerca da 
moral? E depois, como a genealogia da ética dos antigos, última pesquisa de Foucault, colabora para compreendermos nosso presente?

Tomemos, por exemplo, Stirner, Schopenhauer, Nietzsche, o dandismo, Baudelaire, a anarquia, o pensamento anarquista, etc., e teremos uma série de tentativas, sem dúvida inteiramente diversas umas das outras, mas todas elas, creio eu, mais ou menos polarizadas pela questão: é possível constituir, reconstituir uma estética e uma ética do eu? A que preço e em que condições? Ou então: uma ética e uma estética do eu não deveriam finalmente inverter-se na recusa sistemática do eu (como em Schopenhauer)? Enfim, haveria aí uma questão, problemas a serem levantados. Em todo caso, o que gostaria de assinalar é que, de qualquer maneira, quando vemos hoje a significação, ou antes, a ausência quase total de significação e pensamento que conferimos a expressões - ainda que muito familiares e percorrendo incessantemente nosso discurso, como: retornar a si, liberar-se, ser si mesmo, ser autêntico, etc. -, quando vemos a ausência de significação e pensamento em cada uma destas expressões hoje empregadas, parece-me não haver muito do que nos orgulharmos nos esforços que hoje fazemos para reconstituir uma ética do eu. E é possível que nestes tantos empenhos para reconstituir uma ética do eu, nesta série de esforços mais ou menos estanques, fixados em si mesmos, neste movimento que hoje nos leva, ao mesmo tempo, a nos referir incessantemente a esta ética do eu sem contudo jamais fomecer-Ihe qualquer conteúdo, é possível suspeitar que haja uma certa impossibilidade de constituir hoje uma ética do eu, quando talvez seja esta uma tarefa urgente, fundamental, politicamente indispensável, se for verdade que, afinal, não há outro ponto, primeiro e último, de resistência ao poder político senão na relação de si para consigo (FOUCAULT, 2006b, p.305-306).

Com a diferença entre a moral e ética antiga com o momento atual, talvez seja possível pensar em alguns aspectos relevantes a esse tema.

[...] creio que uma experiência moral essencialmente centrada no sujeito não é mais satisfatória atualmente. $\mathrm{E}$, por isso mesmo, um certo número de questões se coloca hoje para nós nos mesmos termos em que elas se colocavam na antiguidade. A busca de estilos de vida, 
tão diferentes quanto possível um dos outros, me parece um dos pontos pelos quais a busca contemporânea pôde se inaugurar antigamente em grupos singulares. A busca de uma forma de uma moral que seria aceitável por todo mundo - no sentido de que todo mundo deveria submeter-se a ela - me parece catastrófica. Entretanto, seria um contra-senso querer fundamentar a moral moderna na moral antiga, fazendo recair o impasse da moral cristã. Se realizei um estudo tão longo foi precisamente para tentar destacar de que modo o que chamamos de moral cristã estava incrustrada na moral europeia, não desde o inicio do mundo cristão, mas desde a moral antiga. (FOUCAULT, 2006b, p. 262263).

Foucault não pretende, como vimos, dizer que a moral antiga é a correta e que devemos seguir cegamente esses princípios. De acordo com Castelo Branco (2008), pode ser um equívoco entender que Foucault considerou o cuidado de si, o uso dos prazeres e a "estética da existência", para cada um cuidar de seu mundo, de maneira subjetiva e particular, pensando unicamente em sua existência e esquecer-se do resto em volta. Para Castelo Branco, Foucault levou em consideração esses pensamentos antigos a partir de uma cuidadosa ontologia e criteriosa reflexão sobre os desafios abertos pelo tempo presente. $O$ processo de singularização somente tem sentido quando culmina na superação do individualismo pela nova aliança do indivíduo com novas formas de vida e novos vínculos. Podemos recusar uma ideia que o cuidado de si como sendo algo exclusivo para apenas alguém extremamente especial e diferente. Pois, como sugere Castelo Branco, a estética da existência, considerada deste ponto de vista, implica em formas criativas de vida.

Seguindo essa mesma linha, Davidson (2006) comenta que existem muitos mal-entendidos e interpretações acerca dos últimos textos de Foucault. Assim, um dos principais erros, comenta o autor, é encaixar essas discursões sobre o cuidado de si dos antigos para o momento atual ou contexto político recente. $\mathrm{O}$ texto de Foucault nos ajuda a compreender e visualizar uma época, mas não tem a intenção de que apliquemos os ensinamentos greco-romanos para nós mesmos. Porém, é importante demonstrar algumas leituras desse momento histórico, para assim perceber de que estamos falando de uma época distante, de outra configuração social e de um

Problemata: R. Intern. Fil. v.6, n. 3(2015), p 146-170 ISSN 2236-8612 
momento específico. Pierre Hadot, estudioso da filosofia antiga, comenta que o exercício espiritual da filosofia dos antigos era sentir como pertencente a um todo; ter uma consciência de fazer parte de um todo cósmico. Para o estudioso, essa "experiência" dos antigos esta relacionada a um todo, a uma totalidade. Sendo assim, trazer a ideia de "cuidado de si" para os dias de hoje seria quase como uma forma de "dandismo" (HADOT, 1989).

Com Foucault (2002), vemos a ética e o "estilo de vida" dos antigos intimamente ligados. Mas, entender esse posicionamento dos antigos talvez seja difícil para nós do século XXI; visto que a experiência grega não parece em nada com o cogito cartesiano. Os gregos pensavam o "si" como sendo um "ele" e não um "eu". Não existia na vida dos gregos a preocupação que mais tarde veríamos em Santo Agostinho ou principalmente em Descartes (VERNANT, 1991, p.328-329). Para ler Foucault e seus estudos da época greco-romana, não precisamos das noções modernas de subjetividade, pois o que vemos é outro momento, outra situação (DAVIDSON, 2006).

In his last writings Foucault expressed concern that the ancient principle "Know thyself" had obscured, at least for us moderns, the similarly ancient requirement that we occupy ourselves with ourselves, that we care for ourselves. He insisted that we not forget that the demand to know oneself was "regularly associated with the theme of the care of the self." It is in this spirit that I have urged that the care of the self must itself be placed in the context of a style of life, that in order to make sense of the care of the self we must widen our vision to include the style of life that gives form and direction to the self's relation to itself. Classical Greek, Hellenistic, and Roman thought, early Christianity, and even the Old Testament all prescribe the care of the self; but the styles of life in which this care is embedded are so different that it affects the notion of care, the notion of the self, and the notions of how and why we are to bear this relation of care to ourselves. One of the great virtues of ancient thought is that knowledge of oneself, care of oneself, and one's style of life are everywhere so woven together that one cannot, without distortion, isolate any of these issues from the entire philosophical thematics of which they form part. If we ignore these dimensions of the moral life, we shall be able to do justice to neither history nor philosophy. And, without doubt worse, we shall not be able to take account of 
ourselves, of who we have become, of how we might become different. (DAVIDSON, 2006, 142-143).

Contudo, muitos anos antes da publicação dos últimos volumes da história da sexualidade, Foucault já tinha falado, pouco é fato, sobre a impossibilidade nos dias de hoje de qualquer formulação de uma moral.

[...] afora as morais religiosas, o Ocidente só conheceu, sem dúvida, duas formas de ética: a antiga (sob a forma do estoicismo ou do epicurismo) articulava-se com a ordem do mundo e, descobrindo sua lei, podia deduzir o princípio de uma sabedoria ou uma concepção da cidade: mesmo o pensamento político do século XVIII pertence ainda a essa forma geral; a moderna, em contrapartida, não formula nenhuma moral, na medida em que todo imperativo está alojado no interior do pensamento e de seu movimento para captar o impensado. [...] O pensamento moderno jamais pôde, na verdade, propor uma moral: mas a razão disso não está em ser ele pura especulação; muito ao contrário, desde o início e na sua própria espessura, ele é um certo modo de ação. Deixemos falar aqueles que incitam o pensamento a sair de seu retiro e a formular suas escolhas; deixemos agir aqueles que querem, sem qualquer promessa e na ausência de virtude, constituir uma moral. Para o pensamento moderno, não há moral possível; pois, desde o século XIX, o pensamento já "saiu" de si mesmo em seu ser próprio, não é mais teoria; desde que ele pensa, fere ou reconcilia, aproxima ou afasta, rompe, dissocia, ata ou reata, não pode impedir-se de liberar e de submeter. Antes mesmo de prescrever, de esforçar um futuro, de dizer o que é preciso fazer, antes mesmo de exortar ou somente alertar, o pensamento, ao nível de sua existência, desde sua forma mais matinal, é, em si mesmo, uma ação um ato perigoso (FOUCAULT, 1999, p.452-453).

Para Foucault, toda formulação de qualquer moral se tornará inviável, pois, todo imperativo está no interior do pensamento e de seu movimento de captar o impensado. $\mathrm{Na}$ antiguidade, víamos esses fundamentos "fora" dos indivíduos; na modernidade, vemos esses fundamentos "dentro" do indivíduo. Com seus estudos sobre os gregos e os romanos, podemos entender um momento da história em que não se pensava como hoje e que existia uma forma de se relacionar consigo e com as regras morais - muito diferente do que se

Problemata: R. Intern. Fil. v.6, n. 3(2015), p 146-170 ISSN 2236-8612 
construiu na modernidade. Foucault, em seus últimos estudos, se interessa em saber como agimos diante de códigos e princípios e como isso nos constitui enquanto sujeitos. $\mathrm{O}$ autor fez uma análise da antiguidade e, se não fosse por sua morte prematura, muito provavelmente teria trazido maiores contribuições para pensar as questões da ética e da moral na contemporaneidade. Contudo, com Foucault, fica uma pergunta: como agimos e como nos constituímos, enquanto indivíduos, diante dos códigos morais e dos princípios éticos de nosso tempo?

\section{Considerações finais}

Foucault, com o segundo e terceiro volume da História da Sexualidade, dá mais valor e importância para a questão do sujeito. Essa mesma problemática - do sujeito -foi ignorada e tratada, em seus trabalhos anteriores, como um problema vindo de fora e até mesmo dependente. Um Foucault mais maduro, em seus últimos trabalhos, se aproxima dos autores da celebrada historiografia francesa, a "Escola dos Annales". Nomes como Phillipe Aries, Paul Veyne, Georges Duby, LucienFebvre, entre outros, são influências importantes, apesar de Foucault (1994) deixar claro que não faz nenhuma história das mentalidades ou dos comportamentos.

A análise de Foucault, sobre a moral e a ética dos grecoromanos, complementa-se muito bem com pesquisas de autores já consagrados sobre o tema, tais como Jean Pierre Vernant (2000), Paul Veyne (2008) e Kenneth James Dover (1978). Foucault, em seu último momento, passa a concordar com uma possível evolução dos fenômenos tanto históricos como sociais. Como argumenta Merquior (1985, p. 211), o autor passa a falar de uma evolução muito lenta do antigo paganismo para o cristianismo e da maneira como tratamos e cuidamos de nós mesmos. De uma mudança da moral exclusiva, quase como um luxo, para uma moral que ambiciona ser para todos e funcionar a partir das instituições e de regras bastante rigorosas. Em suma, um lento processo de mudança dos tempos mais remotos até a modernidade. Deste modo, muito se pode estranhar sobre o novo, se assim podemos chamar, método de Foucault em suas pesquisas. Visto que antes não havia espaço - e se havia era muito pouco - para noções como: sujeito, vontade, cuidado de si, 
entre outras. Em seu problema inicial, por exemplo, a loucura, ou logo depois a formação dos saberes na modernidade, o que vemos é uma preocupação do que $a$ loucura, as ciências humanas, e até mesmo a disciplina, é para os outros (as instituições, a psiquiatria, a medicina, a polícia). Porém, com suas últimas pesquisas, o problema passa a ser, por exemplo, o que o sexo ou as experiências éticas significavam para o próprio sujeito.

Questões sobre o autodomínio, a auto regulação, o autocontrole, passaram a ter importância na obra do autor, não apenas como uma variável constituída e dependente do saber/poder mastambém como uma variável independente. As questões relativas aos indivíduos finalmente ganham uma merecida importância em Foucault. Com o nascimento do cristianismo, vindo de um processo anterior muito propício, o homem, como alguém que confessa -principal ato da prática cristã - é alguém que esta sobre constante vigilância sobre si próprio a partir de uma lei moral (moral cristã).

Paul Veyne (1985), ao pensar o problema da moral em Foucault, comenta que o autor francês tinha muita afinidade, e uma certa particularidade, com o pensamento antigo, bem como tinha disso uma imagem de uma "arte de viver" ou uma moral possível. Veyneentão pergunta: é possível, no interior de sua filosofia, uma moral para Foucault?(VEYNE, 1985,p.993). Segundo o autor, Foucault não tinha pretensões de renovar o pensamento antigo, de renovar a moral e a ética greco-romana como uma alternativa para a ética cristã, mas sim fazer exatamente o contrário. A afinidade maior de Foucault com o pensamento antigo era do trabalho de si sobre si, de uma estetização do sujeito, através de duas morais e de duas sociedades muito diferentes entre si (VEYNE, 1985, p. 933934). Se analisarmos a ótica da moral nos dois últimos volumes da História da Sexualidade:

O diagnóstico da atualidade é aproximadamente este: no mundo moderno, parece ter se tornado impossível fundamentar uma moral. Não existe mais uma natureza ou uma razão diante a qual render-se, nem uma origem com a qual estabelecer uma relação autêntica (no caso da poesia, eu diria, é aparte); a tradição ou a sujeição não são mais que situações de fato. Já não apregoamos mais nem a crise e nem a decadência; as aporias da reduplicação filosófica jamais comoveram aos mortais 
comuns. O que perdura é que os mortais comuns são compostos de sujeitos, de seres desdobrados, que mantêm uma relação ou de consciência ou de conhecimento de si consigo mesmos. É sobre estas bases que julgará Foucault. (VEYNE, 1985, p. 939).

Veyne argumenta que a moral grega desapareceu e que Foucault não tinha o interesse de trazê-la de volta, nem de colocar tudo isso na prática. Porém,um detalhe desta moral, a ideia de um trabalho de si sobre si, parecia apta de adquirir um sentido atual. $O$ "eu" se põe a si mesmo, como uma tarefa a desempenhar, o poder de sustentar uma moral que nem a tradição nem a razão favorecem mais: virar um artista de si mesmo exerceria esta autonomia da qual a modernidade não pode dar conta (VEYNE, 1985, p.939-940).

Foucault, com uma visão ampla das coisas, não pretendeu que nos entregássemos, portanto a uma moral já formada dos pés à cabeça; considerava essas façanhas acadêmicas mortas junto com a filosofia antiga. Mas nos sugeriu uma saída. Levou consigo o resto de sua estratégia. Mas ele, de modo algum, pretendeu apontar uma solução verdadeira ou definitiva; posto que a humanidade se desloca sem parar, sendo também que alguma solução atual revela logo que ela carrega seus perigos, toda solução é então imperfeita, e isso será sempre assim: um filósofo é aquele que, para cada nova atualidade, diagnostica o novo perigo, e mostra uma nova saída. Com esta concepção novíssima de filosofia, a verdade clássica está morta, enquanto que, da confusão historicista moderna se desprende nossa ideia de atualidade. (VEYNE, 1985, p.940-941).

Então, como devemos nos comportar? O que devemos esperar de nós mesmos? A atenção para si mesmo, lembra Foucault, não foi responsável por grandes mudanças nas regras dos homens. Na verdade, de acordo com as pesquisas de Foucault, as percepções do sexo tiveram algumas mudanças durante os seis séculos que o autor estudou. Reconheceu-se que essa prática tinha efeitos colaterais indesejáveis: era desgastante e tendia a perturbar consideravelmente o equilíbrio dos indivíduos. Durante todo o período estudado pelo autor, a sexualidade era vista como uma força natural, cuja capacidade de perturbar a racionalidade foi reconhecida e tratada com grandecautela. "o prazer sexual enquanto substância ética é 
ainda e sempre da ordem da força - da força contra a qual é preciso lutar e sobre a qual o sujeito deve assegurar sua dominação" (FOUCAULT, 2002, p. 72). Foucault argumenta que a difusão do cristianismo coincide com uma importante mudança para perceber a sexualidade como algo negativo. Os cristãos estavam preocupados com a pecaminosidade $\mathrm{e}$ aprenderam a temer sua própria carne como uma fonte da tentação que leva ao mal e a punição. Assim, os cristãos estavam sujeitos a uma lei geral que é ao mesmo tempo a vontade de um deus pessoal (FOUCAULT, 2002).

De acordo com esta moral cristã, o indivíduo só poderia alcançar cumprimento ético se renunciasse as satisfações terrenas e seus desejos puros. A tarefa de vida era de decifrar sua alma e submeter-se a um regime de confissão earrependimento. A moral cristã definiu o eu como um projeto ético. O papel da Igreja foi assumido mais tarde pelo Estado burocrático, a ciência moderna e as profissões liberais seculares: professores, médicos, planejadores demográficos entre outras profissões, usaram como o principal meio a vontade de conhecimento e vontade de poder.

Contudo, ao considerar os estudos de Foucault sobre o pensamento antigo, sabemos queo autor não chegou a problematizar, em uma pesquisa mais completa, a ética nem a moral da qual fazemos parte, muito provavelmente devido a sua morte prematura. Esse assunto, no autor, faz parte das práticas sociais, faz parte das relações de poder, assim como é uma invenção de grupos sobre grupos para demarcar práticas bastante úteis para alguns, tal como demonstrou Nietzsche (1998).

Todavia, uma coisa é certa para Foucault: um redirecionamento para a ética e a moral de épocas passadas não pode ser entendido como uma busca por uma solução em nosso presente; é suspeito procurar apenas no passado soluções éticas para os dilemas atuais. Os tempos eram outros, as situações mais ainda. Quando vemos o trabalho de Foucault, o da problematização da moral antiga, sua principal lição talvez seja a da problematização de nosso presente. Quais são nossas condutas? Como nos relacionamos conosco a partir das regras que nos guiam? (DAVIDSON, 2006). Foucault comenta que atualmente, parece ser difícil que códigos morais, sociais ou religiosos intervenham diretamente nas vidas íntimas dos 
indivíduos e, com isso, façam apenas uma conduta a ser seguida. O conhecimento científico do "eu", do desejo, do inconsciente e da saúde em geral, parece ser mais relevante. Porém, é bom lembrar, como diz Foucault (2006b), que na antiguidade as coisas não funcionavam dessa forma - das morais dependerem das instituições normalizadoras e dos saberes científicos- e o que se viu foi uma utilização de diversas práticas e perspectivas para que cada um aprendesse a se conduzir. Assim, com uma ausência de um imperativo universal ou uma explicação da ciência para nossas formas de organizar e conduzir a vida, as tentativas de codificar e estabelecer uma moral universal parecem não dar certo. Os estudos de Foucault sobre os antigos nos mostram um indicativo - e não um fundamento - para se pensar questões morais nos dias de hoje.

Um dos desafios que podemos tirar em relação aos antigos é o de fazer a vida um objeto de elaboração cuidadosa, uma análise permanente do nosso ser histórico (FOUCAULT, 2006b). Já podemos ver uma possibilidade para pensar a moral na contemporaneidade, assim como indicar uma problematização do pensamento e da relação que cada um pode estabelecer consigo mesmo em diferentes momentos históricos. Esse problema norteou toda a sua última pesquisa: a de fazer e de propor uma história das experiências. Quando observamos as elites gregas e romanas ficamos com a sensação de estranheza por tamanha diferença entre condutas e comportamentos; mas talvez seja essa a intenção. Diante de tantas identidades e condutas estabelecidas por padrões variáveis, pensar a relação que estabelecemos conosco a partir desses padrões parece ser uma atividade interessante.

As análises de Foucault ajudam a entender os fenômenos morais como fazendo parte de um longo processo, que sempre varia e se transforma. Não existe um fator isolado, nem os indivíduos tem plena autonomia de seus atos: é o que nos ensina Foucault. Quando analisamos os fenômenos morais, levando em consideração a genealogia ética de Foucault, o que importa é saber que condições possibilitaram esses fenômenos morais relacionados ao autocontrole. Como ocorrem esses fenômenos? Em que momento histórico? Em que condições específicas? Essas perguntas são fundamentais, para uma análise do que seja a moral em determinado momento histórico. Sua maior contribuição para os estudos dos fenômenos morais é justamente 
no entendimento do autocontrole como uma prática fundamental. Pois, se os seres humanos sempre - e isso é mais bem visto desde a modernidade - se preocupam com a forma de se relacionar consigo e com os outros para a partir disso construir regras para o convívio entre grupos, como então cada um de nós pode se (re)definir enquanto indivíduo? Como cada um pode estabelecer uma relação consigo próprio mediante as regras e exigências do cotidiano? Se assim for, o último projeto de Foucault pode muito bem contribuir para analisar os processos que ocorrem no Ocidente, como também para uma frutífera análise de nosso presente.

\section{Referências}

BINKLEY, S. et al.The Planned and the Unplanned: A Roundtable Discussion on the Legacies of Norbert Elias and Michel Foucault. Foucault Studies, 8 (February), p. 53-77. 2010.

CASTELO BRANCO, Guilherme.Estética da existência, resistência ao poder. RevistaExagium. Volume I - Abril. 2008.

DAVIDSON, A. Ethics as ascetics: Foucault, the history ofethics, and ancient thought. In: G. Gutting (ed.), The Cambridge Companion to Foucault pp. 115-140. Cambridge University Press, Cambridge. 2006.

DOVER, Kenneth James. Greek Homosexuality. Cambridge, MA: HavardUnivertsity Press. 1978.

EWALD, François. Foucault: A norma e o direito. Lisboa: Vega, 1993.

FOUCAULT, Michel. História da sexualidade: o uso dos prazeres. Rio de Janeiro. Graal, 1994.

. O Sujeito e o Poder. In: RABINOW, Paul. DREYFUS,

Hubert. Michel Foucault: uma trajetória filosófica para além do estruturalismo e da hermenêutica. Rio de Janeiro: Forense Universitária, 1995.

História da sexualidade: o cuidado de si. Rio de Janeiro: Graal, 2002.

. História da sexualidade: a vontade de saber. Rio de Janeiro: Edições Graal, 2006a.

. Ditos e escritos: Ética, sexualidade e política. Rio de

Janeiro: Forense Universitária. 2006b. 
HADOT, Pierre. "Le Sage et le monde," in Le Temps de la refléxion, vol. X .Paris: Gallimard., 176-177. 1989.

MACHADO, Roberto. Foucault, a ciência e o saber. Rio de Janeiro: Jorge Zahar, 2009.

MERQUIOR, J. G. Michel Foucault ou o Niilismo de Cátedra. Rio de Janeiro, Nova Fronteira, 1985.

NIETZSCHE, F. Genealogia da moral. São Paulo: Cia. das Letras, 1998.

SMITH, Dennis. The civilizing process and the history of sexuality: comparing Norbert Elias and Michel Foucault. Theory Soc. 28(1):79-100. 1999.

VERNANT, Jean Pierre. "The Individual within the City-State," in Mortals and Immortals, Collected Essays, Froma I. Zeitlin, ed. (Princeton, N.J.: Princeton University Press), 321. 1991. $O$ universo, os deuses, os homens. São Paulo, Companhia das Letras, 2000.

VEYNE, PAUL. Le dernier Foucault et sa morale: in Critique, Paris, Vol. XLIL, nº 471-472, p. 933-941, 1985.

Sexo e poder em Roma. Rio de Janeiro: Civilização

Brasileira, 2008. 